14 Dewsnup DH, Wright DN. In vitro susceptibility of Nocardia asteroides to 25 antimicrobial agents. Antimicrob Agents Chemother 1984;25:165-7.

15 Smego R, Moeller MB, Gallis HA. Trimethoprim-sulfamethoxazole therapy for nocardia infections. Arch Intern Med 1983;143:711-8.

16 Gombert ME. Susceptibility of Nocardia asteroides to various antibiotics including newer beta-lactams, trimethoprim-sulfamethoxazole, amikacin and $\mathrm{N}$-formimidoyl thienamycin. Antimicrob Agents Chemother

17 Adams AR, Jackson JM, Scopa J, Lane GK, Wilson R. Nocardiosis: Diagnosis and management with a report of three cases. Med J Aust 1971;i:669-74

18 Cupps TR, Fauci AS. The vasculitic syndromes. Adv Intern Med 1982;27:315-39.

19 Pusey CD, Lockwood CM. Plasma exchange for glomertiar disease. In: Robinson RR, ed. Nephrology. New York: Springer-Verlag, 1984:1474-85.

20 Cohen J, Pinching AJ, Rees AJ, Peters DK. Infection and immunosuppression: a study of the infective complications of 75 patients with immunologically mediated disease. $Q J$

21 Pinching AJ, Rees AJ, Pussell BA, Lockwood CM, Mitchison RS, Peters DK. Relapses in Wegener's granulomatosis: the role of infection. Br Med J 1980;ii:836-8.

Accepted 29 August 1987.

\section{Motor entrapment neuropathies in the elderly}

Sir: To our knowledge the frequency of entrapment neuropathies in the general population is unknown. From 1 June 1984 to 31 July 1985 we performed a survey on the neurological condition in the elderly in the Republic of San Marino, which is the smallest independent State in the world, located near the Adriatic Coast, within Italy. All people aged $67,72,77,82$ and 87 living in the Republic were invited to undergo a stan1982;21:1011-2. Med 1982;51:1-15.

dardised neurological examination. Three hundred and ninety eight agreed to be examined out of a total sample of 498 but full examination was only possible in 396. People were not specifically asked about sensation disturbances of entrapment neuropathies. However, muscle wasting and loss of muscle strength were recorded during examination. Whenever entrapment neuropathy was suspected patients were further asked about their symptoms and a specific sensation examination was done. Diagnosis of entrapment neuropathy was based on neurological examination showing typical motor and sensory deficits. Whenever possible nerve conduction velocity (NCV) study was performed.

Among 396 people we found 7 (2\%) with an entrapment neuropathy. Details of the patients are shown in the table.

In two patients NCV study was not done, but in these the typical signs and symptoms enabled us to establish a diagnosis of entrapment neuropathy. The design of our study was such that only subjects with motor signs of entrapment neuropathy (with or without sensatory disturbances) were considered abnormal. Therefore our figure may be considered indicative of the frequency of motor entrapment neuropathies in a general population older than 65 years.

Five patients had not previously sought neurological consultation. Their symptoms had been generically attributed to "arthrosis". This shows that entrapment neuropathies although not very frequent in the elderly, may be easily overlooked.

R D'ALESSANDRO

G BENASSI

P MARTINELLI

Clinica Neurologica,

University of Bologna, Via U Foscolo 7 40123 Bologna, Italy.

Accepted 22 September 1987

Table Features of motor entrapment neuropathies found among 396 people aged over 65 years

\begin{tabular}{|c|c|c|c|c|c|c|}
\hline $\begin{array}{l}\text { Age } \\
\text { (yr) }\end{array}$ & Sex & Nerve involved & Site of entrapment & $\begin{array}{l}\text { Sensation } \\
\text { deficit }\end{array}$ & $N C V$ & Underlying factor \\
\hline 67 & 3 & Right ulnar & Elbow & Yes & No & $\begin{array}{l}\text { Elbow fracture aged } \\
45 \text { years } \\
\text { Articular blockade }\end{array}$ \\
\hline 67 & $\hat{j}$ & Right ulnar & Wrist & Doubt & Yes & Mild arthrosis \\
\hline 72 & 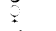 & Left median & Wrist & Yes & No & Moderate arthrosis \\
\hline 77 & $\hat{j}$ & Peroneal & Capitulum fibulae & Yes & Yes & Unknown \\
\hline 77 & ب̂ & Bilateral median & Wrist & Yes & Yes & Moderate arthrosis \\
\hline 77 & † & Right median & Wrist & Yes & Yes & Mild arthrosis \\
\hline 77 & q & Right ulnar & Elbow & Yes & Yes & Moderate arthrosis \\
\hline
\end{tabular}

NCV, nerve conduction velocity.
Relapsing dermatomyositis associated with sarcoidosis

Sir: Two cases of dermatomyositis in association with sarcoidosis have been described, both in Japanese patients. ${ }^{12}$ We report a further case in an Anglo-Japanese man, his illness running a relapsing course over a period of 6 years.

In October 1979 a 56 year old AngloJapanese accountant presented with a 6 month history of pain, stiffness and paraesthesiae in both hands, the symptoms tending to be worse at night but also aggravated by heavy work. He also had swelling of the knuckles of both hands, and an irritating skin rash. He had lost $8 \mathrm{~kg}$ in weight. There was a past history of duodenal ulcer.

On examination he was a thin man (weight $57.5 \mathrm{~kg}$ ). He had an erythematous scaling rash of his lower legs, arms, forehead and back, periorbital oedema, and bilateral axillary lymphadenopathy. Examination of his chest, heart and abdomen was normal. There was no muscle weakness or wasting, though he did have some muscle tenderness. Reflexes were normal and sensation was intact. Full blood count, bone marrow aspirate and trephine biopsy, barium enema, barium meal and intravenous pyelogram were normal. RA latex and ANA were negative. Erythrocyte sedimentation rate was $17 \mathrm{~mm}$ in 1 hour. Creatine kinase was elevated at $384 \mathrm{IU} / 1$ (normal less than 240 IU/1). A chest radiograph showed bilateral apical pleural thickening with a little localised calcification suggestive of previous pulmonary tuberculosis. There was also some interstitial shadowing at both bases, though this resolved after 1 month. Pulmonary function testing indicated a minor restrictive impairment and reduced carbon monoxide diffusion. Lymph node biopsy showed benign reactive changes with follicular hyperplasia, sinus histiocytosis and numerous aggregations of histiocytes in the interfollicular cortex and medulla.

A diagnosis of dermatomyositis was made. His symptoms fluctuated over the next 5 years. The CK was persistently mildly elevated until the most recent relapse. From 1980-1982 he had only mild rash and muscle stiffness. In early 1982 he was given a 3 week course of steroids with resolution of his symptoms. Six months later he had a recurrence of skin rash and developed paraesthesiae which resolved without treatment in 2 months.

In November 1983 he complained of a 2 month history of general malaise and muscle tenderness and was found to have mild proximal weakness (MRC grade 4-5). This resolved without treatment over the next 3 